Contato do autor: cristhian.demarco@unoesc.edu.br

\title{
OS ATOS ADMINISTRATIVOS NA SOCIEDADE DE INFORMAÇÃO E A EFICÁCIA DOS DIREITOS FUNDAMENTAIS
}

\author{
ADMINISTRATIVE ACTS ON THE INFORMATION SOCIETY AND THE \\ EFFECTIVENESS OF FUNDAMENTAL RIGHTS \\ Cristhian Magnus de Marco \\ Universidade do Oeste de Santa Catarina - Unoesc - Santa Catarina - Brasil \\ Hewerstton Humenhuk \\ Universidade do Oeste de Santa Catarina - Unoesc - Santa Catarina - Brasil
}

\begin{abstract}
Resumo: $O$ presente artigo discorre sobre a validade dos atos administrativos e sua interatividade com a sociedade de informação, pautada em uma exegese a partir dos direito fundamentais. Essa interpretação dos atos administrativos a partir do Estado Constitucional de Direito e das diretrizes emanadas dos direitos fundamentais, sugerem uma reorientação dos juízos de validade dos atos administrativos, porquanto os direitos fundamentais, além de condicionantes formais de validade da ordem jurídica, em decorrência da posição hierárquica superior em que se encontram, também assumem posição de condicionantes materiais. Destarte, como consequência da hodierna sociedade informacional, o uso de tecnologias em evolução a intensificam o uso da informação pelo ser humano o que redimensiona o papel da atividade administrativa. A Administração Pública, além de liderar ou fomentar o processo de inovação tecnológica, possui a necessidade de incorporar as características precípuas da sociedade de informação e o dever de disseminar as possibilidades de acesso à informação através de atos administrativos válidos e eficazes. Nesse sentido, 0 texto defender que a atividade administrativa está vinculada à garantia e prevalência dos direitos fundamentais, o que reorienta os juízos de vigência e validade dos atos administrativos na sociedade de informação, a fim de buscar não só observância do princípio da legalidade, mas também a maior otimização possível dos direitos fundamentais.

Palavras-chave: Direitos fundamentais; Sociedade da Informação; Atos Administrativos.
\end{abstract}

Abstract: This article discusses the validity of administrative acts and their interaction with the information society, based on an exegesis from the fundamental right. This interpretation of administrative acts from the constitutional rule of law and the guidelines issued by the fundamental rights, suggest a reorientation of the validity of judgments of administrative acts, because fundamental rights, beyond formal conditions of validity of the law, according to the position in the upper hierarchy which are, also assume material 
constraints position. Thus, as a result of today's information society, the use of evolving technologies to enhance the use of information for the human being which resizes the role of administrative activity. The Public Administration, as well as lead or encourage the process of technological innovation, has the need to incorporate its primary characteristics of the information society and the duty to disseminate the possibilities of access to information through valid and effective administrative acts. In this sense, the text argue that administrative activity is subject to guarantee and prevalence of fundamental rights, which reorients the validity of judgments and validity of administrative acts in the information society, in order to seek not only the principle of legality, but also the greatest possible optimization of fundamental rights.

Keywords: Fundamental rights; Information Society; Administrative acts.

\section{Introdução}

O modelo normativo a partir do século $X X$, e a constitucionalização da Administração Pública sob a égide do Estado Constitucional de Direito, ensejou uma série de mudanças na atividade administrativa. Os atos administrativos, além de estarem adstritos ao princípio da legalidade formal, encontram-se condicionados a observância e prevalência dos direitos fundamentais.

Nesse sentido, o presente artigo, busca fazer uma interpretação dos atos administrativos a partir do Estado Constitucional de Direito e das diretrizes emanadas dos direitos fundamentais, o que sugere uma reorientação dos juízos de validade dos atos administrativos.

Em um primeiro momento registram-se algumas questões pontuais sobre os atos administrativos: conceituação, vigência, validade e eficácia inseridos no Estado Constitucional de Direito, o que, invariavelmente, redimensiona os juízos axiológicos dos atos administrativos e seus desdobramentos entre a validade e eficácia.

Em um segundo momento, demonstrar-se-á conceitos e características da sociedade de informação e os impactos que a tecnologia causa na necessidade de produção de atos administrativos dotados de efetividade e validade a partir da sociedade informacional.

Em um terceiro momento, remonta-se a teoria dos direitos fundamentais e toda sua fundamentalidade no Estado Constitucional de Direito, descrevendo as gerações de direitos jusfundamentais e suas nuances, além de 
como estes direitos encontram-se inseridos como parte nuclear em um Estado Social e Democrático de Direito.

Finalmente, como forma de interligação do assunto proposto, abordase a vinculação da atividade administrativa na eficácia e aplicabilidade dos direitos fundamentais. Nesse diapasão, as diretrizes dos direitos fundamentais encontram-se intimamente ligadas aos juízos de validade e vigência dos atos administrativos, uma vez que a Administração Pública é quem possui as maiores possibilidades de realizar a otimização possível dos direitos fundamentais. Ainda como forma de complementação, externar-se-á o controle da atividade administrativa, não somente a partir da legalidade formal, mas também como limitadora de atuação do agente público a partir de juízos de valores plasmados nos ditames do Estado Constitucional de Direito e dos direitos fundamentais.

\section{Questões pontuais sobre a validade dos atos administrativos}

\subsection{0 conceito de Ato Administrativo}

A atividade administrativa se externa no mundo dos fatos através de atos jurídicos chamados atos administrativos. Essa exteriorização da Administração Pública produz efeitos jurídicos no exercício da atividade administrativa, seja reconhecendo, modificando ou extinguindo direitos, bem como, impondo restrições ou obrigações, sob o pano de fundo da observância da legalidade (MEDAUAR 2003, p.148).

Muitos são os conceitos ensinados pela doutrina do que vem a ser o ato administrativo. Apenas a título de ilustração, mister trazer algumas conceituações. Para Diógenes Gasparini, ato administrativo é toda prescrição, juízo ou conhecimento, predisposta à produção de efeitos jurídicos, expedida pelo Estado ou por quem lhe faça as vezes, no exercício de suas prerrogativas e como parte interessada numa relação, estabelecida na conformidade ou compatibilidade da lei, sob o fundamento de cumprir finalidades assinaladas no sistema normativo, sindicável pelo Judiciário (GASPARINI 1995, p.62). 
$\mathrm{O}$ ato administrativo constitui-se na exteriorização da vontade de agentes da Administração Pública, amparados no regime de direito público, visando à produção de efeitos jurídicos, com o escopo de atender ao interesse público". Para Marçal Justen Filho (2005, p.185), ato administrativo "é uma manifestação de vontade funcional apta a gerar efeitos jurídicos, produzida no exercício de função administrativa".

Sem aprofundar nas inúmeras definições e teorias esposadas acerca do ato administrativo, pode se chegar a conclusão que o ato administrativo é toda manifestação ou declaração unilateral de vontade praticada pela Administração Pública, ou seu agentes delegados, que, agindo nesta qualidade, através de um regime jurídico próprio, tenha por escopo dispor sobre um direito ou impor obrigações aos administrados ou a si própria, interligado à prestação de um serviço público ou desempenho de uma atividade administrativa, estando, ainda, sujeito ao controle de legalidade e legitimidade pelo Poder Judiciário.

\subsection{Breves considerações sobre a vigência, validade e eficácia do Ato} Administrativo no Estado Constitucional de Direito

Os atos administrativos para serem considerados válidos, devem, necessariamente, ser formados pelos seguintes requisitos: agente competente, objeto, forma, motivo ${ }^{1}$ e fim. Além destes pressupostos inerentes ao ato administrativo, devem também passar por um juízo que leve em consideração a sua perfeição, validade e eficácia, sendo o juízo de perfeição "a observância dos procedimentos relativos à sua formação, que, ao serem atendidos,

\footnotetext{
${ }^{1}$ Segundo Lugon, "cumpre aqui registrar que, nos termos da Lei Maior vigente, as decisões administrativas impendem motivação. Assim, não se está pregando uma discricionariedade num vazio de fundamentação; continua havendo a vinculação, só que esta se desloca do terreno da pretensa literalidade, que a hermenêutica recusa, para um obrigatório nexo já não mais com a lei, e sim com o direito. De lembrar-se, no ensejo, que a obrigatoriedade de motivação elimina praticamente a discricionariedade, em face da teoria dos motivos determinantes, pois, uma vez explicitado o fundamento do ato, fica a validade deste dependendo da procedência do espeque aduzido. À conseqüente redução da discricionariedade no decidir deve corresponder um aumento da discricionariedade no interpretar, faculdade que constitui tarefa de uma advocacia pública qualificada e prestigiada". LUGON, Luiz Carlos de Castro. Ética na Concretização dos Direitos Fundamentais. Revista de Doutrina da 4a a $^{-}$Região, Porto Alegre, n. 19, ago. 2007.Disponívelem:http://www.revistadoutrina.trf4.gov.br/artigos/edicao019/Luiz_Lugon.htm>Ac esso em 25 set. 2007.
} 
possibilitam a produção de efeitos jurídicos configurando sua exequibilidade" (BORTOLI 2003, p.152).

Ainda em relação ao Juízo de validade, vigência e eficácia do ato administrativo, escreve Bortoli (2003, p.152):

\begin{abstract}
A vigência de um ato administrativo é identificada com o período de sua permanência no ordenamento jurídico, a sua dimensão temporal. O Juízo de validade é utilizado para verificar se o ato administrativo atende às exigências legais formais contidas no ordenamento jurídico, considerando-se sua adequação aos comandos normativos previstos nas normas de patamar superior. A eficácia do ato administrativo vai ser observada a partir do momento que ele possa produzir os efeitos para os quais foi editado.
\end{abstract}

Os atos administrativos também podem ser extintos, seja por decurso do prazo, por desaparecimento do seu objeto e dos sujeitos e pela caducidade, seja pela extinção provocada pela invalidação, revogação, cassação, decaimento ou contraposição de um ato por outro e pela retirada.

A Administração Pública pode revogar seus próprios atos, por questões de conveniência e oportunidade, sendo que, a revogação é uma modalidade de desfazimento dos atos administrativos privativa da Administração Pública, devendo obedecer às regras de hierarquia e competência específicas. Quanto à invalidação, tanto a Administração como o Poder Judiciário podem invalidar ou anular os atos administrativos, desde que eivados de vícios de legalidade ou constitucionalidade. Neste caso, estar-se-á diante de um ato viciado não admitindo a revogação. A matéria de invalidação e revogação já foi objeto de análise pelo próprio Supremo Tribunal Federal - STF, ao editar a súmula 473 que dispõe que a Administração pode anular seus próprios atos, quando eivados de vícios que os tornem ilegais, porque deles não se originam direitos; ou revogá-los, por motivo de conveniência ou oportunidade, respeitados os direitos adquiridos e ressalvados, em todos os casos, a apreciação judicial.

Percebe-se que o STF adotou o entendimento do poder-dever quando verificada a ilegalidade dos atos da Administração Pública, podendo anular seus próprios atos baseado no princípio da Autotutela.

Ressalta-se ainda que os atos administrativos podem ser convalidados nos casos de nulidade relativa (anulabilidade), quando o ato viciado puder ser 
refeito de forma válida no presente e o interesse público exigir sua convalidação, desde que não haja prejuízos a terceiros. A convalidação tem efeitos retroativos à data da prática do ato eivado de vícios sanáveis, alcançando em regra os vícios de competência, no caso, quando se opera a ratificação, além da forma, quando não imprescindível à configuração do ato, vedado, salvo situações excepcionais, nos casos de vícios de motivo e finalidade.

Partindo do pressuposto da sujeição da Administração e de seu atos ao princípio da legalidade, que se encontra dotada de complexidade inerente ao Estado de Direito, ${ }^{2}$ o próprio modelo normativo constitucional estabelecido após a constitucionalização da Administração Pública a partir do século $X X$, sugere uma reorientação dos juízos de validade dos atos administrativos. Nesse sentido:

A reorientação dos juízos de validade, compreendidos como subsunção dos casos concretos aos comandos normativos formais do ordenamento jurídico, é exigência dos modernos Estados constitucionais que incorporaram em seus ordenamentos axioma éticos-políticos orientadores das ações estatais, e, de modo particular, da atuação da Administração pública (BORTOLI 2003, p.99).

O modelo normativo das Cartas Constitucionais modernas, nascidas a partir do próprio Estado Democrático de Direito, pode ser assim concebido nos dizeres de Bortoli (2003, p.100-101):

a) no plano formal, pelo princípio da legalidade, em virtude do qual todo poder público - legislativo, judicial e administrativo - está subordinado a leis gerais e abstratas que disciplinam suas formas de exercício, e cuja observância se acha submetida a controle de legitimidade por parte de juízes separados do Estado e independentes;

b) no plano substancial, pela funcionalização de todos os poderes do Estado a serviço da garantia dos direitos fundamentais dos cidadãos,

\footnotetext{
${ }^{2}$ Segundo Celso Antônio Bandeira de Mello, "deve-se, desde logo, começar por frisar que o próprio Estado de Direito, como se sabe, é encontrar-se, em quaisquer de suas feições, totalmente sujeitado aos parâmetros da legalidade. Inicialmente, submisso aos termos constitucionais, em seguida, aos próprios termos propostos pelas leis, e, por último, adstrito à consonância com os atos normativos inferiores, de qualquer espécie, expedidos pelo Poder Público. Deste esquema, obviamente, não poderá fugir agente estatal algum, esteja ou não no exercício de 'poder' discricionário". In: BANDEIRA DE MELLO, Celso Antônio. Discricionariedade e Controle Jurisdicional, 2. ed. São Paulo: Malheiros, 1998, p. 10-11.
} 
mediante a incorporação limitativa em sua Constituição dos deveres públicos correspondentes, quer dizer, das proibições de lesar os direitos de liberdade e das obrigações de dar satisfação aos direitos sociais, assim como dos correlativos poderes dos cidadãos de ativar a tutela judicial.

Denota-se que a partir das ponderações acima explicitadas, especificamente ao primeiro item, se estabelece um juízo quanto à vigência normativa, e do segundo item verifica-se a validade da norma. Os atos administrativos como forma de exteriorização da função normativa da Administração Pública, para serem considerados atos legítimos dentro de um Estado de Direito, devem, ser analisados sob os juízos de vigência e validade.

Estes aspectos dos atos administrativos e das suas redefinições a partir de um Estado constitucional de Direito, acaba por desencadear "uma teoria jurídica positivista crítica, conhecida como Garantismo Jurídico, ${ }^{3}$ que redefine os conceitos de validade, vigência e eficácia e compreende a garantia dos direitos fundamentais" (BORTOLI 2003, p.102), designando um tipo nuclear dos sistemas jurídicos. A eficácia do ato sob o enfoque garantista pode externar atos válidos, mas ineficazes, bem como, atos eficazes, mas inválidos, devendo ocorrer a observação entre modelos normativos garantistas e antigarantistas.

\footnotetext{
${ }^{3}$ Conforme se extrai do trecho da sentença do Juiz Alexandre Morais da Rosa, que decidiu que a prefeitura de Joinville (SC) deveria abrir matrícula para todas as 2.948 crianças em fila de espera em educação infantil, fundamentando sua decisão com base no garantismo jurídico: "O garantismo jurídico apesar de ter sua origem vinculada ao Direito Penal, evoluiu para alcançar foros de Teoria do Direito. Luigi Ferrajoli indica quatro frentes garantistas. A primeira está vinculada à revisão da teoria da validade, que preconiza uma diferenciação entre validade/material e vigência/formal das normas jurídicas. A segunda frente pretende 0 reconhecimento de uma dimensão substancial da democracia, suplantando o caráter meramente procedimental desta. Já na terceira, do ponto de vista do Juiz, se propõe uma nova maneira de ver a sujeição à lei somente por ser lei - aspecto formal - pretendendo que esta sujeição se dê somente quando conjugadas a forma e o conteúdo das normas. Por fim, observa a relevância da ciência jurídica, cujo papel deixa de ser meramente descritivo, mas ganha contornos críticos e de projeção do futuro. Com efeito, a Teoria Geral do Garantismo, entendida como modelo de Direito, está baseada no respeito à dignidade da pessoa humana $e$ seus Direitos Fundamentais, com sujeição formal e material das práticas jurídicas aos conteúdos constitucionais. Isso porque, diante da complexidade contemporânea, a legitimação do Estado Democrático de Direito deve suplantar a mera democracia formal, para alcançar a democracia material, na qual os Direitos Fundamentais devem ser respeitados, efetivados e garantidos, sob pena da deslegitimação paulatina das instituições estatais. Dito de outra forma, tendo-se em vista a supremacia Constitucional dos direitos positivados no corpo de Constituições rígidas ou nela referidos (CF, art. $5^{\circ}$, $\S 2^{\circ}$ ), como a brasileira de 1988 , e do princípio da legalidade, a que todos os poderes estão submetidos, surge a necessidade de garantir esses direitos a todos os indivíduos". In: Revista Consultor Jurídico, 30 de maio de 2003. http://conjur.estadao.com.br/static/text/26546,1. Acesso em 25. set. 2007.
} 
O Garantismo rompe com a tradicional doutrina positivista que "reduzia a validade de uma norma à sua eficácia ou à sua mera validade formal ao demonstrar que uma norma, para ser válida, deve obedecer, não somente aos seus requisitos procedimentais, mas também aos substanciais" (BORTOLI 2003, p.102).

Cademartori (1999, p.80) escreve que o 'pano de fundo teórico-geral do garantismo', constitui-se também de quatro predicados distintos que se podem imputar às normas, a saber: justiça, vigência, validade e eficácia (efetividade). Nesse sentido é que o Garantismo se insere dentro de um modelo positivista próprio do Estado moderno, consubstanciado pela forma jurídica do Estado, em conformidade com o princípio da legalidade, desde que o mesmo seja apreendido dentro do conceito de um juspositivismo crítico, em contraposição ao juspositivismo dogmático. Aí reside a diferença substancial entre normas vigentes, válidas e eficazes.

Os atos administrativos, para serem considerados válidos, além da observância do juízo de fato, a partir da sua vigência, deverão passar pela análise de um juízo axiológico ou argumentativo que determinará se o seu conteúdo coaduna com as determinações existentes em níveis superiores do ordenamento, ao passo que a eficácia do ato administrativo deve corresponderse na maior medida possível ao modelo normativo a que está adstrito, oportunizando, por exemplo, verificar "situações em que sendo eficazes os atos, não podem ser considerados válidos, e sendo válidas as normas que servem de fundamento para a prática dos atos, não são necessariamente eficazes" (BORTOLI 2003, p.106).

Dentro deste pressuposto, a confrontação entre validade e eficácia do ato administrativo permite a reflexão dentro de um juízo no qual as normas de hierarquia inferior são contratadas com 0 teor valorativo das normas superiores, especialmente no contexto das normas de direitos fundamentais.

\section{Os atos administrativos na sociedade de informação}


Hodiernamente, a revolução trazida pelos meios tecnológicos da comunicação com o surgimento dos computadores e, sobretudo, com a utilização da Internet, constituem a base tecnológica para um novo tipo de organização das sociedades a partir da era tecnológica da informação da Sociedade.

Castells (2003, p.7) escreve que a tecnologia da informação é hoje o que a eletricidade foi na Era Industrial, em nossa época a Internet poderia ser equiparada tanto a uma rede elétrica quanto motor elétrico, em razão de sua capacidade de distribuir a força da informação por todo o domínio da atividade humana.

No modo de desenvolvimento informacional, as relações técnicas de produção difundem-se por todo o conjunto de relações e estruturas sociais, ou seja, há uma íntima ligação entre cultura e forças produtivas, que tende a trazer o surgimento de novas formas históricas de interação, controle e transformação social, pois as instituições transformam a tecnologia. "Como nossa prática é baseada na comunicação, e a Internet transforma o modo como nos comunicamos, nossas vidas são profundamente afetadas por essa nova tecnologia da comunicação (CASTELLS 2003, p.10).

A Sociedade da Informação é caracterizada pela atual forma de interação das relações pessoais e no direcionamento dos aspectos econômicos, políticos, jurídicos e sociais, através de uma interligação tecnologia-sociedade. A interatividade através do processo de inovação é externado como crescimento da distância entre o hodierno mundo veloz da inovação tecnológica e a lentidão do mundo da proteção sócio-constitucional (Rodotà apud Doneda 2000, p.120). As ultrapassadas soluções reguladoras de um determinado fenômeno técnico acabam ficando muito aquém das necessidades contemporâneas.

Castells (2003, p.43) de uma forma geral tece algumas críticas de que a tecnologia não determina a sociedade e nem a sociedade descreve o curso da transformação tecnológica, porquanto muitos fatores, inclusive "criatividade e iniciativa empreendedora, intervêm no processo de descoberta científica, inovação tecnológica e aplicações sociais de forma que o resultado final depende de um complexo padrão interativo". À toda evidência, a sociedade usa 
a tecnologia na propagação da informação. Segundo Lévy (2003, p.21), "não somente as técnicas são imaginadas, fabricadas e reintegradas durante seu uso pelos homens, como também é o próprio uso intensivo de ferramentas que constitui a humanidade como tal (junto com a linguagem e as instituições sociais complexas)". Escreve Castells (2003, p.57-60) que a sociedade informacional tem como principal subsídio a característica específica da informação, uma vez que as tecnologias em evolução intensificam o uso da informação pelo ser humano.

Feitos estes breves esclarecimentos, é aqui que o papel da informação traduz-se em novo paradigma para a Administração Pública através da tecnologia. A própria Diretiva 2002/58 da Comunidade Europeia pressupõe que o desenvolvimento da sociedade da informação caracteriza-se pela introdução de novos serviços de comunicações eletrônicas. Hoje o acesso a redes digitais está disponível a custos razoáveis para um vasto público. Essas interações tecnológicas via digital têm grandes capacidades e possibilidades de tratamento de dados pessoais. E a Administração Pública, além de liderar ou fomentar o processo de inovação tecnológica, possui a necessidade de incorporar as características precípuas da sociedade de informação e o dever de disseminar as possibilidades de acesso à informação, inclusive para o controle dos atos administrativos.

Dito de outro modo, o setor público, que é um dos espelhos das estruturas sociais, acaba produzindo um processo de modificação, a fim de adequar-se ao novo modelo de sociedade informacional. Isso faz com que a participação democrática, a horizontalização das relações, transparência, agilidade, o controle social, a eficiência e eficácia são parâmetros que se impõem para Administração Pública a realidade contemporânea de globalização, descentralização e de inovações tecnológicas (MOREIRA, MAIA 2013). ${ }^{4}$

\footnotetext{
4 "A guisa de estabelecer-se na história recente fatos que corroborem essa ideia, cita-se um exemplo de serviço inovador fornecido ao cidadão, em contrapartida, é o do projeto "Rede Cidadão-Informação para a Cidadania" implementada pela Prefeitura de Recife. Esse foi o primeiro projeto de Freenet da América Latina, proporcionando acesso discado gratuito à Internet desde julho de 1993. O serviço teve uma taxa de acesso mensal a suas páginas superior a 35.000 visitas, em meados de 1996, uma das mais altas do Brasil nessa época. Aproximadamente $40 \%$ dos acessos eram, então, internacionais, com um crescimento recente de acessos nacionais devido à disseminação do uso da Internet no Brasil. Mas poder-se-ia
} 
Atualmente, a prática de ações voltadas para a gestão da informação na administração pública já têm refletido seus efeitos sobre a população. Iniciativas como a declaração de imposto de renda, a emissão de certidões, protocolos, consultas, multas, editais e outros serviços disponibilizados via atividade administrativa que têm sido disponibilizados aos cidadãos via Internet por Estados, Municípios e União.

Com o avanço da tecnologia, a própria Administração Pública instituiu uma nova modalidade licitatória: o pregão eletrônico através do advento da Lei Federal n. 10.520 de 17 de julho de 2002 (BRASIL 2002), posteriormente regulamentado pelo Decreto n. 5450 de 31 de maio de 2005 (BRASIL 2005). O pregão eletrônico é um interessante exemplo de inserção dos atos administrativos na sociedade de informação. É uma modalidade licitatória utilizada pela Administração Pública para contratar bens e serviços, independentemente do valor estimado. O pregão eletrônico visa, basicamente, aumentar a quantidade de participantes e baratear o processo licitatório, permitindo a ampliação da disputa licitatória, com a participação de maior número de empresas de diversos pontos da Federação, já que é dispensada a presença dos contendentes, uma vez que é realizado pela internet através de provedores específicos. Tornou efetivamente mais eficiente e barato o processo licitatório, por permitir a simplificação de vários atos administrativos e de muitas das etapas burocráticas que tornavam morosa a contratação com a administração pública.

Outro exemplo bem sucedido do uso da tecnologia pela Administração Pública lastreada na sociedade informacional foi o advento da Lei n. 12.527 de novembro de 2001 (BRASIL 2011), a chamada Lei de Acesso à Informação -

perguntar: Esse não era um projeto elitista, uma vez que grande parte da população mais carente não tem acesso a computadores? A Freenet também se associou a outros projetos municipais para disseminar o uso de computadores e da Internet entre famílias pobres da periferia urbana e outros. O investimento em infraestrutura não foi também esquecido. Esses projetos, juntamente com iniciativas como a de uma rede metropolitana de fibras óticas, com tecnologia ATM, que estava à época sendo implantada pela companhia telefônica local em cooperação com a universidade e a prefeitura, configuravam uma estratégia local que a prefeitura de Recife buscava implementar com a participação de organizações públicas e privadas. Mais recentemente poderíamos citar como iniciativas a declaração de imposto de renda, a emissão de certidões, protocolos, consultas, multas, editais e outros serviços que têm sido disponibilizados aos cidadãos via Internet por Estados, Municípios e mesmo pela União no espírito do que se convencionou chamar Governo eletrônico" (MOREIRA, MAIA 2013). 
LAI, que regulamenta o direito constitucional do cidadão ao acesso a informações produzidas ou detidas pelo Governo. Entrou em vigor no dia 16 de maio de 2012. Referida legislação garante o direito ao acesso à informação previsto no art. no artigo $5^{\circ}$, inciso XXXIII do Capítulo I da Constituição Federal de 1988 (BRASIL 1988). ${ }^{5}$

Todas estas adoções de Tecnologias da Informação para prática de atos administrativos exteriorizados pela Administração Pública, acaba impondo uma condição operacional básica de sobrevivência do Estado e no cumprimento das leis, face aos desafios atuais diante da necessidade de informação de órgãos governamentais e da população. Cresce, portanto, a necessidade de maior eficácia possível do direito fundamental à informação pública, através de atos administrativos produzidos para tal desiderato, tendo como pressuposto uma utilização racional, transparente, viável, acessível, compreensível e contínua.

\section{A teoria dos direitos fundamentais}

Para compreensão acerca da teoria dos Direitos Fundamentais ${ }^{6}$, é necessário que se faça uma breve análise filosófica e histórica demonstrando a evolução dos direitos fundamentais através dos tempos.

\footnotetext{
${ }^{5}$ Art. 5을 inc. XXXIII da Constituição Federal dispõe que: "todos têm direito a receber dos órgãos públicos informações de seu interesse particular, ou de interesse coletivo ou geral, que serão prestadas no prazo da lei, sob pena de responsabilidade, ressalvadas aquelas cujo sigilo seja imprescindível à segurança da sociedade e do Estado". A Constituição também tratou do

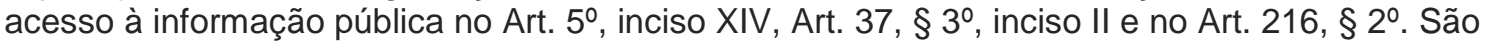
estes os dispositivos que a Lei de Acesso a Informações regulamenta, estabelecendo requisitos mínimos para a divulgação de informações públicas e procedimentos para facilitar e agilizar o seu acesso por qualquer pessoa.

${ }^{6}$ Ingo Sarlet, diferenciando a definição de direitos fundamentais, direitos humanos e direitos naturais escreve: "os direitos fundamentais são os direitos do ser humano reconhecidos e positivados na esfera do direito Constitucional positivo de determinado Estado; a expressão 'direitos humanos', por sua vez, 'guardaria relação com os documentos de direito internacional, por referir-se àquelas posições jurídicas que se reconhecem ao ser humano como tal, independentemente de sua vinculação com determinada ordem Constitucional e que, portanto, aspiram à validade universal, para todos povos e tempos, de tal sorte que revelam um inequívoco caráter supranacional (internacional)'. Os direitos naturais não se equiparam aos direitos humanos uma vez que a positivação em normas de direito internacional já revela a dimensão histórica e relativa dos direitos humanos". In: SARLET, Ingo Wolfgand. A Eficácia dos Direitos Fundamentais. Porto Alegre: Livraria do Advogado, 1998, p. 31 . O constitucionalista português J.J Canotilho ainda outra diferenciação, no que tange aos direitos fundamentais para com os direitos do homem: "direitos do homem são direitos válidos para
} 
A ligação primordial dos direitos fundamentais à liberdade e à dignidade humana, nos seus teores históricos e filosóficos, demonstrará a pertinência desses direitos, ao qual são inerentes da pessoa humana, delineando toda sua universalidade como ideal. Segundo Bonavides (2000, p.516), "a universalidade se manifestou pela vez primeira, com a descoberta do racionalismo francês da Revolução, por ensejo da célebre Declaração dos Direitos do Homem de 1789". Escreve Maliska (2001, p.39) que "a fase anterior aos acontecimentos do final do século XVIII é representada, no âmbito dos direitos fundamentais, pelas cartas e declarações inglesas". A partir da Declaração francesa, notou-se que esta tinha um grau de abrangência muito mais significativo do que as declarações inglesas e americanas, uma vez que "se dirigiam a uma camada social privilegiada (os barões feudais), quando muito a um povo ou a uma sociedade que se libertava politicamente, conforme era o caso das antigas colônias americanas, ao passo que a Declaração Francesa de 1789 tinha por destinatário o gênero humano (BONAVIDES 2000, p.516). Como se vê, a Declaração francesa designava um caráter humano de grande valia, assumindo sua universalidade. Neste contexto histórico inerente aos direitos fundamentais, observa-se que ali os direitos do homem munidos também do direito de liberdade, ganharam força e legitimidade. Externar-se-á então dentro dos direitos fundamentais as características de direitos naturais, inalienáveis e sagrados, caracteres próprios das sociedades democráticas. É mister ainda que se nota a enorme influência da Declaração francesa nas constituições ocidentais.

As cartas de características eminentemente liberais, eram limitadas através da autoridade do Estado, designando desta forma separar os poderes nas suas respectivas funções (legislativo, executivo e judiciário), e consubstanciando a efetivação da declaração dos direitos. A partir destas configurações de direitos, surgem os direitos de primeira geração, representando os direitos civis e políticos, que postulavam uma atividade negativa ${ }^{7}$ por parte do Estado, não violando o cunho individual destes direitos.

todos os povos e em todos os tempos (dimensão jusnaturalista-universalista)" (CANOTILHO, 1999, p. 369).

7 "É uma classificação de Jellinek e fazem ressaltar na ordem dos valores políticos a nítida separação entre a Sociedade e o Estado. Sem o reconhecimento dessa separação, não se 
Não obstante a isso, surgem novos modelos de constituições, que primavam não só pela proteção individual dos indivíduos, mas também por direitos sujeitos à prestações, denominados de direitos da segunda geração, ou seja, os direitos sociais, culturais e econômicos concernentes às relações de produção, ao trabalho, à educação, à cultura e à previdência.

Já as sociedades modernas, nas suas constituições, começaram a prestigiar o surgimento de novos direitos, denominados de terceira geração (direitos ao desenvolvimento, à paz, à propriedade sobre o patrimônio comum, à comunicação e ao meio ambiente). Também há que se falar em direitos de quarta geração, que prescrevem a globalização política (direito à democracia, 0 direito à informação e direito ao pluralismo).

Com a universalidade da Declaração francesa de 1789, começou a surgir os ditames da democracia e dos direitos fundamentais, consoante a lição de Boutmy citado por Bonavides (2000, p.516): "foi para ensinar o mundo que os franceses escreveram". Portanto, para se ter um conceito e idealizar uma Constituição, é mister que se coloque que os textos constitucionais são permeados pelos direitos fundamentais, adquirindo estes, lugar privilegiado nos ditames das Cartas Magnas. Os direitos fundamentais inicialmente, "assumem o caráter de direitos negativos, que importam uma restrição à ação do Estado para, posteriormente, assumirem uma postura ativa, exigindo ações positivas do Estado" (MALISKA 2001, p.42).

\subsection{Os Direitos Fundamentais como parte nuclear na Constituição em um Estado Social Democrático de Direito}

A premissa para se formar um Estado Social, e que este esteja consubstanciado no princípio democrático, é sem dúvida sua ligação correlacionadora com os direitos fundamentais. Quando as constituições elaboram, em seus primeiros artigos, os fundamentos do Estado e da Sociedade, estes somente alcançam efetividade social mediante concretização

pode aquilatar o verdadeiro caráter anti-estatal dos direitos de liberdade, conforme tem sido professado com tanto desvelo teórico pelas correntes do pensamento liberal de teor clássico." (BONAVIDES, 2000, p. 517-518). 
dos postulados normativos referentes aos direitos fundamentais. Para se ter uma ideia mais nítida de Estado Social Democrático de Direito, Sundfeld (1993, p.55) preconiza:

Para definir juridicamente o Estado brasileiro de hoje - não só ele: a maioria dos Estados civilizados - basta construir a noção de Estado Social Democrático de Direito, agregando-se aos elementos ainda há pouco indicados, a imposição, ao Estado, do dever de atingir objetivos sociais, e a atribuição, aos indivíduos do correlato direito de exigi-los. ${ }^{8}$

Nesse sentido surge outra variante, o desenvolvimento econômico, que se consubstancia como condição para realização desta prestação dos direitos sociais. Com isso, o Estado tem por consequência a incrementar o desenvolvimento econômico, efetuando assim uma função que não é inerente da concepção de Estado Social. Seguindo a linha de raciocínio, Maliska (2001, p.53) explica que um Estado Social Democrático de Direito poderia definir-se não pela atuação direita, ou não, na economia, mas sim pelo comprometimento Constitucional com os direitos sociais, pela definição das atribuições do Estado, ainda no tocante à prestação direta dos serviços públicos, quando tais serviços sejam de prestação gratuita e universal, como são saúde, educação e assistência social.

O Estado de Direito e os direitos fundamentais estabelecem uma relação recíproca, pois o Estado de Direito, como a própria nomenclatura já diz, necessita da dependência, funcionalidade e garantia dos direitos fundamentais para ser este Estado de Direito, de tal sorte que os direitos fundamentais como consequência, requerem para sua efetivação, a positivação e normatização, bem como as garantias por parte do Estado de Direito. Com este

\footnotetext{
${ }^{8}$ Ainda segundo Sundfeld (1993, p. 55): "São elementos do conceito de Estado Democrático de Direito: a) criado e regulado por uma Constituição; b) os agentes públicos fundamentais são eleitos e renovados periodicamente pelo povo e respondem pelo cumprimento de seus deveres; c) o poder político é exercido, em parte diretamente pelo povo, em parte por órgãos estatais independentes e harmônicos, que controlam uns aos outros; d) a lei produzida pelo Legislativo é necessariamente observada pelos demais poderes; e) os cidadãos, sendo titulares de direitos, inclusive políticos, podem opô-los ao próprio Estado. Em termos sintéticos, - Estado Democrático de Direito é a soma e o entrelaçamento de: constitucionalismo, república, participação popular direita, separação de poderes, legalidade e direitos (individuais e políticos)."
} 
entendimento, é inequívoco o esclarecimento de Sarlet (1998, p.61), baseado na lição de Schneider, aduzindo que os direitos fundamentais passam a ser considerados, para além de sua função originária de instrumentos de defesa da liberdade individual, elementos da ordem jurídica objetiva, integrando um sistema axiológico que atua como fundamento material de todo ordenamento jurídico.

Apesar da ausência de norma expressa no direito constitucional pátrio qualificando a nossa República como um Estado Social e Democrático de Direito (art. 1ํㅡ, caput, refere-se apenas os termos democrático e Direito), não restam dúvidas - e nisso parece existir um amplo consenso na doutrina - de que nem por isso o princípio fundamental do Estado Social deixou de encontrar guarida em nossa Constituição (SARLET 1998, p.61).

Os direitos fundamentais, além de condicionantes formais de validade da ordem jurídica, em decorrência da posição hierárquica superior em que se encontram, também assumem posição de condicionantes materiais, ou seja, passaram a vincular a ordem jurídica sob o prisma do conteúdo de tais direitos, integrando, ao lado da definição da forma de Estado, do sistema de governo e da organização do poder, a essência do Estado Constitucional, se inserindo, neste sentido, não apenas parte da Constituição formal, mas também elemento nuclear da Constituição material.

Oportuno ainda esclarecer que os direitos fundamentais, por seu teor e significado dentro da Ordem Constitucional, preconizam a possibilidade de um sistema aberto. Nessa diretriz, Pereira de Farias ressalta os direitos fundamentais dentro do ordenamento constitucional "tem o sentido de uma 'cláusula aberta', de forma a respaldar o surgimento de 'direitos novos' 'não expressos na Constituição de 1988 mas nela implícitos", sejam em decorrência do regime e princípios por ela adotados, ou em virtude de tratados internacionais em que o Brasil seja parte, reforçando, assim, o sentido do disposto no art. $5^{\circ}, \S 2^{\circ}$ da Carta Magna de $1988 .^{9}$

\footnotetext{
${ }^{9}$ Este é a interpretação dada por Maliska (2001) acerca da lição de Pereira de Farias na sua obra Colisão de Direitos. No direito comparado, podemos destacar o entendimento equivalente de VIEIRA DE ANDRADE, José Carlos. Os Direitos Fundamentais na Constituição Portuguesa de 1976. In: O Direito à Educação e a Constituição, 1987, p.69.
} 
Sarlet (1998, p.74) advoga o entendimento que é inviável a sustentação no direito Constitucional pátrio, de uma concepção de que os direitos fundamentais formam um sistema fechado no âmbito da Constituição. Segundo ainda aquele Autor, "se reconhecendo a existência de um sistema dos direitos fundamentais, este necessariamente será, não propriamente um sistema lógico-dedutivo (autônomo e auto-suficiente), mas, sim, um sistema aberto e flexível, receptivo a novos conteúdos e desenvolvimentos".

\section{A vinculação da atividade administrativa na eficácia e aplicabilidade dos direitos fundamentais}

Todo dispositivo da Constituição Federal, especialmente aqueles referentes aos direitos fundamentais, são possuidores de determinado grau de eficácia e aplicabilidade, devido a normatização imposta pelo Poder Constituinte. O principal dispositivo que dá guarida a esta preleção acerca dos direitos fundamentais, é $\circ \S 1^{\circ}$ do artigo $5^{\circ}$ da Constituição Federal de 1988, que dispõe: "As normas definidoras dos direitos e garantias fundamentais têm aplicação imediata" (BRASIL 1988). É a partir deste artigo que se vislumbra a aplicabilidade das normas constitucionais de direitos fundamentais e sua garantia frente aos atos da Administração (HUMENHUK 2004).

As normas constitucionais assumem diversas formulações conforme a função que exercem dentro do campo de ação da Constituição. Assim, externam-se de acordo com as distintas formas de positivação. Contudo, sem adentrar profundamente nas variadas e diversas classificações das normas constitucionais $^{10}$ que permeiam os direitos fundamentais, oportuno para 0 presente estudo designar apenas as suas generalidades.

\footnotetext{
10 Para um estudo aprofundado acerca das diferentes classificações, no tocante às técnicas de positivação das normas constitucionais, podem ser consultadas na doutrina, dentre outras, as classificações de: SILVA, Jose Afonso da. Aplicabilidade das Normas constitucionais. $3^{\text {a }}$ ed. São Paulo: Malheiros, 1998; BASTOS, Celso Ribeiro e BRITTO, Carlos Ayres. Interpretação e aplicabilidade das Normas Constitucionais. São Paulo: Saraiva, 1982; DINIZ, Maria Helena. Norma Constitucional e seus Efeitos. São Paulo: Saraiva, 1989.; BARROSO, Luiz Roberto. O Direito Constitucional e a Efetividade de suas Normas. 3 ㅇ ed. Rio de Janeiro: Renovar, 1996.
} 
Devido à variedade considerável de direitos fundamentais outorgados na nossa Lei Maior de 1988, as normas constitucionais estão em diversas disposições, diferentes entre si no que tange a técnica de sua positivação no conteúdo da Constituição. Segundo Sarlet (1998, p.233), fica notório que "a carga eficacial será diversa em se tratando de direito fundamental proclamado em normas de natureza eminentemente programática (ou - se preferirmos - de cunho impositivo), ou sob forma de positivação que permita, desde logo, o reconhecimento de direito subjetivo ao particular titular do direito fundamental."

A título de elucidação Eros Grau (1988, p.130) explica que as normas programáticas são aquelas que "ao invés de se definirem em fins concretos a serem alcançados, contém princípios e programas (tanto de conduta, quanto de organização), bem como, princípios relativos a fins a cumprir, existem apenas na esfera constitucional".

Em princípio, os nomeados direitos de defesa delineiam um direito subjetivo individual, posto que, se colocam naquelas situações em que a norma constitucional outorga ao particular uma posição ativa subjetiva, ou seja, um poder jurídico, haja vista que, seu uso imediato independe de qualquer prestação alheia ou da Administração Pública (BARROSO 1996, p.106). Alexy (1997, p.96) escreve que os direitos de defesa, na sua dimensão jurídico subjetiva como direitos fundamentais, são agrupados em três categorias a saber: i) direitos ao não impedimento de ações por parte do titular do direito; ii) direitos à não afetação de propriedades e situações jurídicas do titular de direito; iii) direitos à não eliminação de posições jurídicas. Em se tratando de direitos fundamentais de defesa, a presunção em favor da aplicabilidade imediata e a máxima da maior eficácia possível devem prevalecer, não apenas autorizando, mas impondo à Administração Pública e, por conseguinte, aos juízes e tribunais, que apliquem as respectivas normas aos casos concretos, viabilizando, de tal sorte, o pleno exercício desses direitos (inclusive como direitos subjetivos), outorgando-lhes, portanto, sua plenitude eficacial e, consequentemente, sua efetividade (SARLET 1998, p.254).

Contudo, o mesmo não acontece com os nomeados direitos a prestações, uma vez que, estes direitos de cunho prestacional, muitos deles 
positivados a partir de normas programáticas, necessitam, em princípio de interposição do legislador para atuação e execução por parte da Administração Pública, para que sejam permeados de aplicabilidade e eficácia plena. Deve-se analisar a abrangência da norma disposta no art. $5^{\circ}, \S 1^{\circ}$ da Constituição Federal. Pois esta é resultado de diferentes influências, expelidas por outras Constituições sobre o Constituinte pátrio. Estas influências foram exercidas principalmente pelo art. 18/1 da Constituição Portuguesa e 0 art. $1^{\circ}$, inciso III, da Lei Fundamental da Alemanha. ${ }^{11}$ Ao analisar o alcance e o significado da norma do art. $5^{\circ}, \S 1^{\circ}$ da Lei Maior de 1988, Maliska (2001, p.106) assevera que:

Quanto à questão de que o dispositivo estaria reduzido às normas do art. $5^{\circ}$, tal entendimento pode ser afastado pela simples interpretação literal da norma, que refere a 'direitos e garantias fundamentais'. Desta forma, a localização tópica da norma, não serve como critério para justificar tal entendimento restritivo. Uma interpretação sistemática e teleológica conduzirá aos mesmos resultados, uma vez que utilizar a expressão 'direitos e garantias fundamentais', o constituinte buscou atingir a totalidade das normas do Título II, o que inclui também os direitos políticos, de nacionalidade e os direitos sociais e não apenas os direitos e garantias individuais e coletivos.

Todavia, entramos numa divergência que não quer cessar no seio da doutrina jurídico-constitucional brasileira; a saber: o alcance da expressão: aplicação imediata dos direitos e garantias fundamentais. A norma em evidência não pode atentar contra a natureza das coisas, a tal ponto que relativa parte dos direitos fundamentais alcançaria sua eficácia nos termos e na medida da lei (SARLET 1998, p.236). No entanto, Grau (1988 p.303) salienta que:

\begin{abstract}
Aplicar o direito é torná-lo efetivo. Dizer que um direito é imediatamente aplicável é afirmar que o preceito no qual é inscrito é auto-suficiente, que tal preceito não reclama - porque dele independe - qualquer ato legislativo ou administrativo que anteceda a decisão na qual se consume a sua efetividade (...). Preceito
\end{abstract}

\footnotetext{
${ }^{11}$ Escreve Sarlet, que estas influências, exercidas sobre o nosso constituinte, para designar o art. $5^{\circ}, \S 1^{\circ}$ da Constituição Federal, tanto na doutrina nacional quanto no direito comparado (inobstante de formas menos acentuada), ainda não pressupõe um patamar de consenso no que tange ao significado e efetivo alcance do referido artigo citado acima. Assim, este passou a configurar o teor de temas controversos na seara do Direito constitucional. In: A Eficácia dos Direitos Fundamentais, p. 235. Neste sentido, PIOVESAN, Flávia. Direitos Humanos e o Direito constitucional Internacional. $2^{\text {a }}$ ed. São Paulo: Max Limonad, 1997, p. 63.
} 
imediatamente aplicável vincula, em última instância, o Poder Judiciário. Negada pela Administração Publica, pelo Legislativo ou pelos particulares a sua aplicação, cumpre ao Judiciário decidir pela imposição de sua pronta efetivação.

Seguindo ainda a essa linha de pensamento, o Poder Judiciário tem a função garantir e reproduzir o direito, além de produzir, baseado nos princípios jurídicos. Diante disto, esta produção do direito, não quer dizer que o Judiciário assuma a função Legislativa, todavia, tem por objetivo assegurar a pronta garantia e execução do direito, fundamentado na Lex Suprema. Tal designação não viola o princípio da Separação dos Poderes porque, segundo o autor, o Legislativo tem o monopólio do exercício da função legislativa e não da função normativa (GRAU 1988, p.303).

Isto posto, a referida norma do $\S 1^{\circ}$ do art. $5^{\circ}$ da Constituição Federal é dotada de vigência e eficácia jurídica. ${ }^{12}$ Esta norma assevera a aplicabilidade imediata dos direitos fundamentais, exprimindo uma função vinculante, norteadora e referencial das atividades administrativas, tanto pelos seus agentes, quanto pelos seus órgãos estatais, estando, estes, obrigados formal e materialmente, haja vista a indisponibilidade dos Poderes Públicos em relação a estes direitos.

Os direitos fundamentais prestacionais, devido a maior responsabilidade do Estado no ordenamento jurídico, tem sua exegese externada de forma diversa dos direitos fundamentais de defesa, no que tange a sua aplicabilidade e posterior efetivação. Conforme a lição de Canotilho (1994, p.365):

A força dirigente e determinante dos direitos a prestações (econômicos, sociais e culturais) inverte, desde logo, o objeto clássico da pretensão jurídica fundada num direito subjetivo: de uma pretensão de omissão dos poderes públicos (direito a exigir que o Estado se abstenha de intervir nos direitos, liberdades e garantias) transita-se para uma proibição de omissão (direito a exigir que o

\footnotetext{
${ }^{12}$ Segundo Eros Roberto Grau, baseado nas obras de Antoine Jeammaud e Oscar Correas, define a eficácia jurídica como "quando realizada a conformidade de uma situação jurídica concreta ao modelo que constitui a norma (reconhecimento efetivo, a determinado sujeito, de que beneficia, segundo a lei, por um direito, visto que cumpridos os requisitos prévios para tanto, nela estabelecidos); ou (...) quando tiver sido produzida a norma individual que interpreta ou atualiza a norma aplicada." In: A ordem econômica na Constituição de 1988, p. 319.
} 
Estado intervenha activamente no sentido de assegurar prestações aos cidadãos).

Ainda segundo o constitucionalista lusitano, na seara dos direitos fundamentais a prestações, a Constituição dirigente se consubstancia a um máximo de "<desejabilidade constitucional>" de direitos prestacionais sociais, que passa a relacionar-se genericamente, com uma interposição do legislador necessária, derivada da subordinação de uma efetividade constitucional para sua consecução (CANOTILHO 1994, p.365). Esta interposito do legislador, visa a ser uma forma de assegurar que os direitos prestacionais tenham a referida aplicabilidade imediata e a sua carga eficacial seja a máxima possível, vinculando a atividade da Administração Pública, conforme a vontade do constituinte. Segundo Bortoli (2003, p.109-110):

\footnotetext{
Mesmo quando a Administração Pública atua sob o manto da discricionariedade, em que a norma legal não defina nem precise com clareza o que fora programado, o faz sob a habilitação legal e deve observar os limites que the são impostos pelo ordenamento (...) Assim, os princípios constitucionais administrativos são sede de valores fundamentais e dos limites primeiros que vinculam a administração a interesse geral ou ao interesse público.
}

Os direitos fundamentais de cunho prestacional passam a ter certa peculiaridade devido ao seu grau de aplicabilidade imediata e eficácia plena alcançável. De acordo com Clève (2000, p.320-321), as normas constitucionais que possuem uma eficácia jurídica de vinculação, e estas, quando assumem uma dimensão positiva, "condicionam o legislador, reclamando a concretização (realização) de suas imposições; se nem sempre podem autorizar a substituição do legislador pelo juiz, podem, por vezes, autorizar o desencadear de medidas jurídicas ou políticas voltadas para a cobrança do implemento, pelo legislador."

$O$ art. $5^{0}, \S 1^{\circ}$ da Constituição Federal, revela em sua normatividade, uma imposição aos Poderes Públicos de alicerçar a eficácia máxima e imediata factível aos direitos fundamentais. Segundo Piovesan (1997, p.64), "este princípio intenta assegurar a força dirigente e vinculante dos direitos e 
garantias de cunho fundamental". Sarlet (1998) exprime a mesma compreensão, designando a norma do $\S 1^{\circ}$ do art. $5^{\circ}$ uma "espécie de mandado de otimização (maximização)".

À Administração Pública e sua atividade administrativa, "tanto na estrutura judiciária quanto na legislativa ou executiva, é a que tem maiores possibilidades de se tornar ao mesmo tempo garantia e antigarantia de numerosos direitos" (BORTOLI 2003, p.108), cabendo a ela o trabalho e o relativo dever, de colher das normas consagradoras dos direitos fundamentais, a máxima eficácia possível, pois conjeturar a aplicabilidade imediata e a eficácia plena em prol dos direitos fundamentais significa, em última instância, externar toda a fundamentalidade formal da qual nossa Carta Magna é detentora.

\subsection{O Controle da Atividade Administrativa}

A divisão de funções dos Poderes do Estado está fundamentada na ordem democrática que rege o Estado constitucional de Direito, de modo que a fiscalização e o controle recíproco entre os diversos órgãos públicos se consubstanciam em uma realidade atual. A divisão de poderes é seguramente externada como um processo de distribuição e integração racionalizadas das várias funções e órgãos do Estado, de forma a limitar as possibilidades de exercício arbitrário do Poder, garantindo condições da maior eficiência da atuação estatal, com estrito respeito aos direitos e liberdades fundamentais. $O$ jus-filósofo alemão Jürgen Habermas (1997, p.308), entende que a insuficiência da ultrapassada construção clássica do princípio da separação de poderes, passa a defender a irradiação dos direitos fundamentais para todas as esferas do direito, principalmente para aquelas relacionadas à atuação do Estado.

Os princípios constitucionais ${ }^{13}$ como fonte irradiadora e parâmetro do Estado-administrador, assumem o papel de autêntico limite substantivo, e não

\footnotetext{
${ }^{13}$ Ronald Dworkin na sua obra Los Derechos en serio e Robert Alexy com a Teoría de los Derechos Fundamentales, demonstraram a transformação do direito, que passou a ter nos 
meramente formal, do direito administrativo (BAPTISTA 2003, p.42), atuando como normas fundamentais para boa gestão da coisa pública. Nesta concepção, os princípios constitucionais passaram a controlar a Administração Pública, em especial no aperfeiçoamento do controle da Administração Pública quanto aos seus atos discricionários, permitindo uma identificação do ambiente decisório do administrador, em virtude da imposição de parâmetros objetivos de valoração a serem seguidos (BAPTISTA 2003, p.91). O controle imposto pelo Estado constitucional de Direito demarcam o espaço de atuação do administrador. Barroso (2003, p.367) entende que:

\begin{abstract}
O poder discricionário, portanto, encontra limites, como já referido, na finalidade legal da norma que o instituiu, mas também, e primordialmente, nas normas constitucionais. No normal das circunstâncias, como no caso examinado neste estudo, a finalidade legal do ato a ser praticado e as normas constitucionais são limites que convivem harmoniosamente para demarcar o espaço de atuação do administrador, mas é importante registrar que, em caso de conflito insuperável entre esses dois elementos, a supremacia será sempre das normas constitucionais, admitindo-se até mesmo que 0 administrador deixe de dar cumprimento à lei em reverência à Constituição.
\end{abstract}

O progressivo controle da atividade administrativa a partir dos princípios constitucionais, notadamente provocou, e vem provocando, uma auto-revisão do próprio direito administrativo na emanação dos seus atos, não somente sob a égide da legalidade formal, mas também através de limites materiais, adequando-os aos juízos de validade e axiológicos que permeiam toda a atuação da Administração. Andreas Krell (2004, p.54-55) escreve que:

Não há mais dúvidas, no Brasil, de que todo e qualquer ato
administrativo, inclusive o ato discricionário e também aquele
decorrente da valoração administrativa dos conceitos indeterminados
de prognose, é suscetível de um controle jurisdicional mínimo,
baseado nos princípios constitucionais e nos princípios gerais de
Direito. Na atual fase 'pós-positivista', que foi instaurada com a ampla
positivação dos princípios gerais de Direitos nos novos textos
constitucionais, os atos administrativos discricionários não devem ser
controlados somente por sua legalidade, mas por sua juridicidade.
Essa 'principialização' do Direito brasileiro (proibição da
arbitrariedade, razoabilidade, proporcionalidade, igualdade, proteção

princípios constitucionais uma referência capaz de abolir as ideias passadas de que os princípios gerais de direito, os costumes e a analogia é que representavam o sistema jurídico. 
da confiança legítima, etc.) aumentou a margem da vinculação dos atos discricionários.

O controle da atividade administrativa passa a ser uma exigência do Estado constitucional de Direito, sendo fomentado esse controle, a partir de juízos de validade, de fato e de valores dos atos administrativos, com uma abordagem garantista e construído sob a ótica dos direitos fundamentais. Nesse sentido, escreve Bortoli (2003, p.162), baseado nos ensinamentos de Cademartori (1999) e Alexy (1997):

\begin{abstract}
Como sustenta Cardemartori, o controle jurisdicional dos atos administrativos, a partir do paradigma da jurisprudência dos valores, oportuniza uma análise garantista do ato administrativo, na qual os elementos forma, competência e objeto comportam um juízo de fato; e os elementos motivo, conteúdo e finalidade, um juízo valorativo. Tal noção, formulada pela teoria garantista e aplicada aos atos administrativos aproxima-se da concepção elaborada por Alexy, visto que este jurista somente entende como válida a norma cuja fundamentação seja jusfundalmentalmente correta, na medida em que os argumentos the dão fundamento partam de normas constitucionais, dos procedentes jurisprudenciais e dos argumentos práticos gerais desenvolvidos na fundamentação jusfundamental. Entretanto, como ressalta Cardemartori, “(...) o desafio que apresenta tal argumentação jusfundamental, é precisamente, o de construir uma fundamentação jurídico-normativa racional de juízos valorativos, sem que isto implique um apelo a valores transcendentais ou metafísicos, ou seja, não se trata de retomar o paradigma jusnaturalista.
\end{abstract}

Com o aparelhamento tecnológico da Administração Pública inserida cada vez mais na sociedade informacional, repensar os controles e limites dos atos administrativos, a partir dos parâmetros externados pelo Estado Constitucional de Direito, e consequentemente, dos direitos fundamentais, passa a ser quesito indispensável no atuar da Administração Pública, a fim de buscar no sentido axiológico do juízo de validade e vigência do ato administrativo, o escopo final de atender o princípio da legalidade e do interesse público, além de alcançar a maior otimização possível dos direitos fundamentais.

\title{
6. Considerações finais
}


O presente artigo dentro do limite que se propôs, buscou demonstrar a validade dos atos administrativos a partir da vinculação da Administração Pública na consecução da máxima eficácia possível dos direitos fundamentais.

A partir do Estado Constitucional de Direito houve uma reorientação dos juízos de validade dos atos administrativos, não somente a partir da legalidade formal, mas também da vinculação da Administração Pública em buscar a efetivação dos direitos fundamentais. Os juízos de vigência, eficácia e validade dos atos administrativos, a partir da garantia e prevalência dos direitos fundamentais, rompe com a tradicional doutrina positivista que reduzia a validade do ato administrativo à sua legalidade estrita. Isto acaba por desencadear uma nova interpretação para a efetiva validade dos atos administrativos, consignando juízos axiológicos de vigência e validade de acordo com a observância e eficácia dos direitos fundamentais. Tais critérios de validade do ato administrativo ganham ainda mais relevância a partir da sua exteriorização na sociedade de informação, notadamente a partir de exemplos de inserção da tecnologia na atividade administrativa como a Lei de Acesso à Informação.

O catálogo dos direitos fundamentais é parte nuclear no Estado de Direito, e a própria Constituição Federal prescreve mecanismos para sua eficácia e aplicabilidade. Dentro desse pressuposto, a atividade administrativa está vinculada à garantia e prevalência dos direitos fundamentais, o que reorienta os juízos de vigência e validade dos atos administrativos, a fim de buscar não só observância do princípio da legalidade, mas também a maior otimização possível dos direitos fundamentais.

O controle da Administração Pública é exigência do Estado Constitucional de Direito, sendo fomentado esse controle a partir da validade dos atos administrativos, através de uma abordagem garantista, delineando um juízo axiológico sob a ótica argumentativa jusfundamental.

Construir uma fundamentação dos atos administrativos de acordo juízos valorativos de validade e vigência, plasmado na teoria dos direitos fundamentais e no garantismo jurídico é exigência do Estado Constitucional de Direito e do próprio direito administrativo contemporâneo, fazendo com que a 
atividade administrativa alcance a maior eficácia e aplicabilidade dos direitos fundamentais e atenda o princípio da legalidade e do interesse público.

\section{Referências bibliográficas}

ALEXY, Robert. Teoria de Los Derechos Fundamentales. Tradução espanhola por Ernesto Garzón Valdés. Madrid: Centro de Estudios Constitucionales, 1997.

BANDEIRA DE MELLO, Celso Antônio. Discricionariedade e Controle Jurisdicional. 2. ed. São Paulo: Malheiros, 1998.

BAPTISTA, Patrícia. Transformação do Direito Administrativo. São Paulo: Renovar, 2003.

BARROSO, Luiz Roberto. O Direito Constitucional e a Efetividade de suas Normas. 3. ed. Rio de Janeiro: Renovar, 1996.

BARROSO, Luis Roberto. Temas de Direito Constitucional. tomo II, São Paulo: Renovar, 2003.

BASTOS, Celso Ribeiro e BRITTO, Carlos Ayres. Interpretação e aplicabilidade das Normas Constitucionais. São Paulo: Saraiva, 1982.

BONAVIDES, Paulo. Curso de Direito Constitucional. 10. ed. São Paulo: Malheiros, 2000.

BORTOLI, Adriano De. A Validade dos Atos Administrativos e a Vinculação da Administração Pública aos Direitos Fundamentais. In: CADEMARTORI, Luiz Henrique (org.). Temas de Temas de Política e Direito Constitucional Contemporâneos.. Florianópolis: Editora momento Atual, 2003.

BRASIL. Constituição (1988). Constituição Federal da República Federativa do Brasil: promulgada em 05 de outubro de 1988. 36. ed. São Paulo: Atlas, 2012. (Coleção Manuais de Legislação).

Lei 10.520, de 17 de julho de 2002. Disponível em: <http://www.planalto.gov.br/ccivil_03/Leis/2002/L10520.htm> . Acesso em 10/01/2015.

. Decreto 5.450, de 31 de maio de 2005. Disponível em: <http://www.planalto.gov.br/ccivil_03/_ato2004-2006/2005/decreto/d5450.htm> Acesso em 10/01/2015.

.LEI 12.527, Lei de Acesso à Informação. 18 de Novembro de 2011. 
Brasília. Disponível em: < http://www.planalto.gov.br/ccivil_03/_Ato20112014/2011/Lei/L12527.htm> Acesso em 10/01/2015.

CADEMARTORI, Luiz Henrique Uquhart. Discricionariedade Administrativa no Estado Constitucional de Direito. Curitiba: Juruá, 2001.

CADEMARTORI, Sérgio. Estado de Direito e legitimidade: uma abordagem garantista. Porto Alegre: Livraria do advogado, 1999.

CANOTILHO, José Joaquim Gomes. Constituição Dirigente e Vinculação do Legislador. Contributo para Compreensão das normas constitucionais programáticas. Coimbra: Coimbra Editora, 1994.

CANOTILHO, José Joaquim Gomes. Direito Constitucional e Teoria da Constituição. 3. ed. Coimbra: Almedina, 1999.

CASTELLS, Manuel. A sociedade em rede. A era da informação: economia, sociedade e cultura. Tradução Roneide Venâncio Majer. 7. ed. São Paulo: Paz e Terra, 2003.

CLĖVE, Clémerson. Merlin. A Fiscalização Abstrata da Constitucionalidade no Direito Brasileiro. 2. ed. São Paulo: Revista dos Tribunais, 2000.

DINIZ, Maria Helena. Norma Constitucional e seus Efeitos. São Paulo: Saraiva, 1989.

DONEDA, Danilo Cesar Maganhoto. Considerações iniciais sobre bancos de dados informatizados e o direito à privacidade. In: TEPEDINO, Gustavo (Org.) Problemas de direito civil-constitucional. Rio de Janeiro: Renovar, 2000.

GASPARINI, Diógenes. Direito Administrativo. 4. ed. São Paulo: Saraiva, 1995.

GRAU. Eros Roberto. A ordem econômica na Constituição de 1988. 4. ed. São Paulo: Malheiros, 1988.

GRAU, Eros Roberto. Direitos, Conceitos e Normas Jurídicas. São Paulo: Revista dos Tribunais, 1988.

HABERMAS, Jürgen. Direito e Democracia entre Facticidade e Validade. Tradução por Flávio Beno Siebeneichler. 2o v. Rio de Janeiro: Templo Brasileiro, 1997.

HUMENHUK, Hewerstton. $O$ direito à saúde no Brasil e a teoria dos direitos fundamentais. Jus Navigandi, Teresina, a. 8, n. 227, 20 fev. 2004. Acesso em $25 . \quad$ set. 2007.2 Disponível em: $<$ http://jus2.uol.com.br/doutrina/texto.asp?id=4839>.

JUSTEN FILHO, Marçal. Curso de Direito Administrativo. São Paulo: Saraiva, 2005. 
KRELL, Andreas J. Discricionariedade Administrativa e Proteção Ambiental. 0 Controle dos Conceitos Jurídicos Indeterminados e a Competência dos Órgãos Ambientais. Proto Alegre: Livraria do Advogado, 2004.

LÉVY, P. A inteligência coletiva: por uma antropologia do ciberespaço. 4. ed. São Paulo: Loyola, 2003.

LUGON, Luiz Carlos de Castro. Ética na Concretização dos Direitos

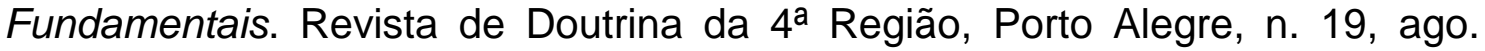
2007.

http://www.revistadoutrina.trf4.gov.br/artigos/edicao019/Luiz_Lugon.htm>Acess o em 25 set. 2007.

MALISKA, Marcos Augusto. O Direito à Educação e a Constituição. Porto Alegre: Fabris, 2001.

MEDAUAR, Odete. Direito Administrativo Moderno. 7. ed. São Paulo: RT, 2003.

MOREIRA, Alex. MAIA, Cláudio Gomes. In: Datagramazero. Tecnologias da informação, mudança e administração pública. Revista de Informação - v.14, n.2, abr/13. http://www.dgz.org.br/abr13/Art_04.htm. Acesso em 10. Jan. 2015.

PIOVESAN, Flávia. Direitos Humanos e o Direito constitucional Internacional. 2. ed. São Paulo: Max Limonad, 1997.

ROSA, Alexandre Morais da. In: Direito à Educação. Juiz manda prefeitura matricular 2.948 crianças em SC. Revista Consultor Jurídico, 30 de maio de 2003. http://conjur.estadao.com.br/static/text/26546,1. Acesso em 25. set. 2007.

SARLET, Ingo Wolfgand. A Eficácia dos Direitos Fundamentais. Porto Alegre: Livraria do Advogado, 1998.

SILVA, Jose Afonso da. Aplicabilidade das Normas constitucionais. 3. ed. São Paulo: Malheiros, 1998.

SUNDFELD, Carlos Ari. Fundamentos de Direito Público. 2. ed. São Paulo: Malheiros, 1993.

VIEIRA DE ANDRADE, José Carlos. Os Direitos Fundamentais na Constituição Portuguesa de 1976. Coimbra: Almedina, 1987. 